\title{
Extra-axial chordomas
}

\author{
S Evans ${ }^{1}$, Z Khan $^{1,2}$, L Jeys ${ }^{1}$, R Grimer ${ }^{1}$ \\ ${ }^{1}$ Royal Orthopaedic Hospital NHS Foundation Trust, UK \\ ${ }^{2}$ Rehman Medical Institute, Pakistan
}

ABSTRACT

INTRODUCTION A chordoma is a slow growing malignant tumour of notochordal origin. A tumour with histological features that are identical to those of a chordoma may arise outside the axial skeleton. To date, there is little in the literature documenting their clinical course.

METHODS Our large orthopaedic oncology database was used to document the clinical course of extra-axial chordoma.

RESULTS Over a 30-year period, 131 patients diagnosed with a chordoma were treated at our unit. Only three (2.3\%) of these cases were extra-axial chordomas: one in the femur, one in the ulna and one in the proximal fibula. All underwent surgical resection.

CONCLUSIONS In view of the rarity of this tumour and the difficulty in confirming its diagnosis, we suggest that any suspected case is discussed with a specialist sarcoma multidisciplinary team so that the correct diagnosis can be achieved and treatment tailored accordingly.

\section{KEYWORDS}

Extra-axial - Chordoma - Clinical course

Accepted 21 October 2015

CORRESPONDENCE TO

Scott Evans, E: scottevans@nhs.net

Chordomas are slow growing malignant tumours of primitive notochordal origin and are almost exclusively distributed in the axial skeleton, with approximately half occurring in the sacrococcygeal region, a third in the spheno-occipital area and the remainder along the rest of the vertebral column. ${ }^{1} \mathrm{~A}$ tumour with identical histological features to a chordoma may arise outside the axial skeleton, ${ }^{2}$ the so-called extra-axial chordoma. ${ }^{3}$ These are extremely rare, and survival, recurrence and the rates of metastasis are therefore not well known.

The relative rarity and slow growth of these tumours account for why most large clinical studies over many years have been based on cases collected involving variable treatments. We describe our experience of the management of 3 cases of extra-axial chordomas over a 30 -year period.

\section{Methods}

A retrospective search was conducted of a large prospective tumour database to identify all patients with a chordoma treated at our unit over a 30-year period. Overall, 131 patients with the diagnosis of chordoma were found, with only $3(2.3 \%)$ extra-axial chordomas. The diagnosis was confirmed following a multidisciplinary team (MDT) review of the patients' clinical history, pertinent radiological imaging and histological findings. Patient demographics were recorded, along with the site of their disease, management and overall outcome (Table 1).

\section{Results}

\section{Patient 1}

A 36-year-old man was referred with a 6-month history of pain and gradual swelling over the ulnar border of his wrist. Clinical examination revealed a firm mass related to the distal ulna with generalised restriction of wrist movement. An expansile lesion in the distal ulna was evident on plain radiography, with non-specific features on magnetic resonance imaging (MRI) (Fig 1). A needle biopsy identified a tumour that was histologically most consistent with a chordoma or chondroid chondrosarcoma. As a definitive histological diagnosis could not be made, an open biopsy was performed to obtain more tissue, which confirmed the diagnosis of an extra-axial chordoma.

Further to extensive discussion in our MDT meetings, surgical resection was recommended to achieve clearance. Staging studies confirmed the lesion to be isolated. After careful surgical planning, $14 \mathrm{~cm}$ of the distal ulna was excised and the wrist was immobilised in an above-elbow cast for four weeks, which was converted to a below-elbow cast for a further eight weeks postoperatively.

The patient made an uncomplicated recovery and histological analysis of the resection specimen again confirmed the diagnosis of an extra-axial chordoma, resected with a wide margin (Fig 2). At the ten-year follow-up visit, he was alive with no evidence of disease. He had a Musculoskeletal Tumor Society score of $60 \%$ and a Toronto extremity salvage score of $51 \%$. 


\begin{tabular}{|c|c|c|c|c|c|c|c|c|c|}
\hline Case & $\begin{array}{l}\text { Age / } \\
\text { sex }\end{array}$ & Site & $\begin{array}{l}\text { Clinical } \\
\text { presentation }\end{array}$ & Treatment & Margin & $\begin{array}{l}\text { Time to } \\
\text { recurrence }\end{array}$ & $\begin{array}{l}\text { Time to } \\
\text { metastasis (site) }\end{array}$ & $\begin{array}{l}\text { Time to } \\
\text { death }\end{array}$ & $\begin{array}{l}\text { Follow-up } \\
\text { duration }\end{array}$ \\
\hline 1 & $59 \mathrm{M}$ & Fibula & Pain, swelling & $\begin{array}{l}\text { Wide resection, soft tissue } \\
\text { reconstruction }\end{array}$ & Wide & - & - & - & 107 weeks \\
\hline 2 & $36 \mathrm{M}$ & Ulna & Pain, swelling & Excision & Wide & - & - & - & 520 weeks \\
\hline 3 & $68 \mathrm{M}$ & Femur & Fracture & $\begin{array}{l}\text { Extra-articular resection and } \\
\text { endoprosthetic replacement }\end{array}$ & Close & 132 weeks & 156 weeks (lung) & 220 weeks & 156 weeks \\
\hline
\end{tabular}

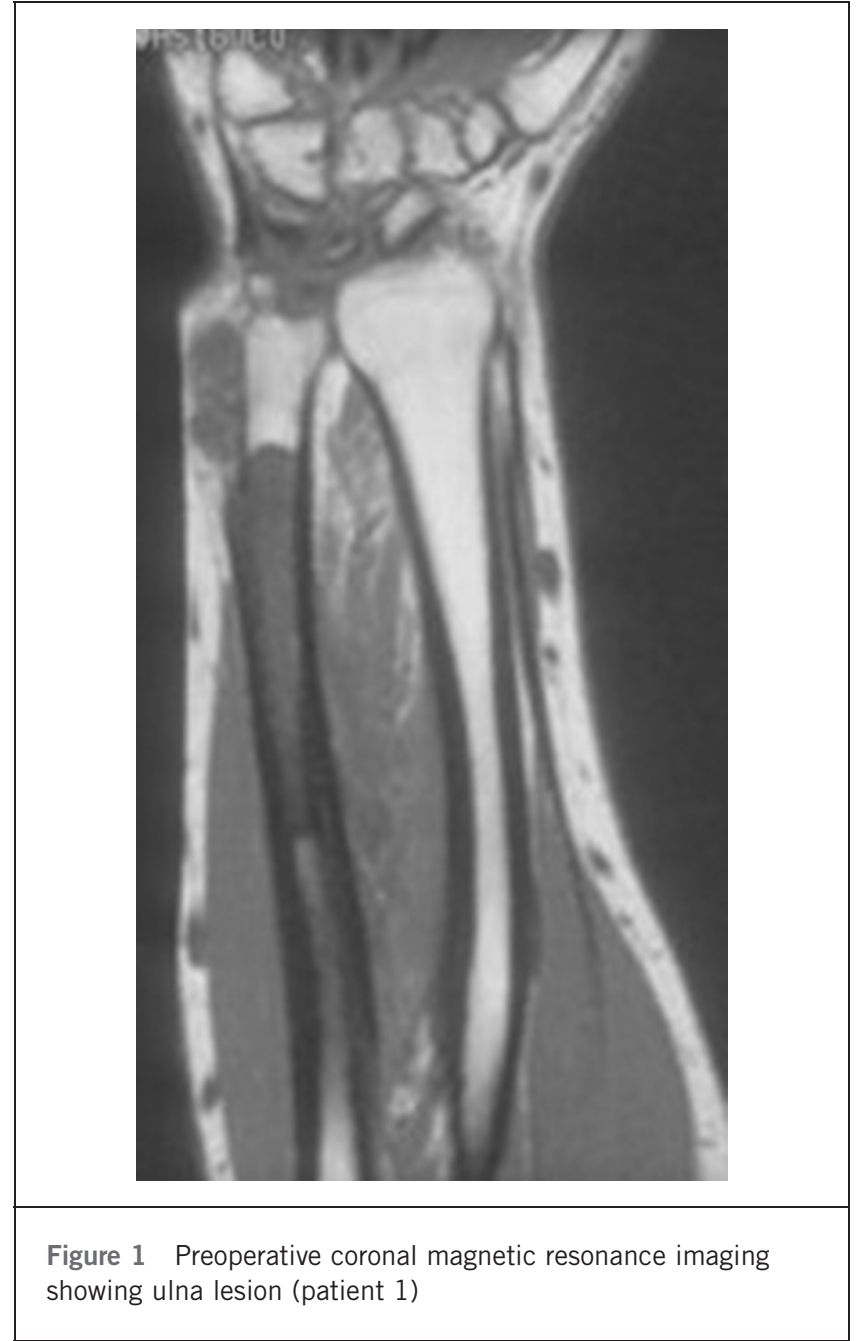

\section{Patient 2}

A 59-year-old man presented with a 5-month history of pain and swelling to the lateral aspect of the knee. Plain radiography and MRI revealed an expansile destructive lesion in the proximal fibula (Figs 3 and 4). A needle biopsy was inconclusive. An open biopsy was therefore performed and analysis suggested an extra-axial chordoma. Routine preoperative assessment confirmed a solitary lesion. After MDT discussion, the patient underwent resection of the proximal fibula with reconstruction of the lateral ligament and soft tissues

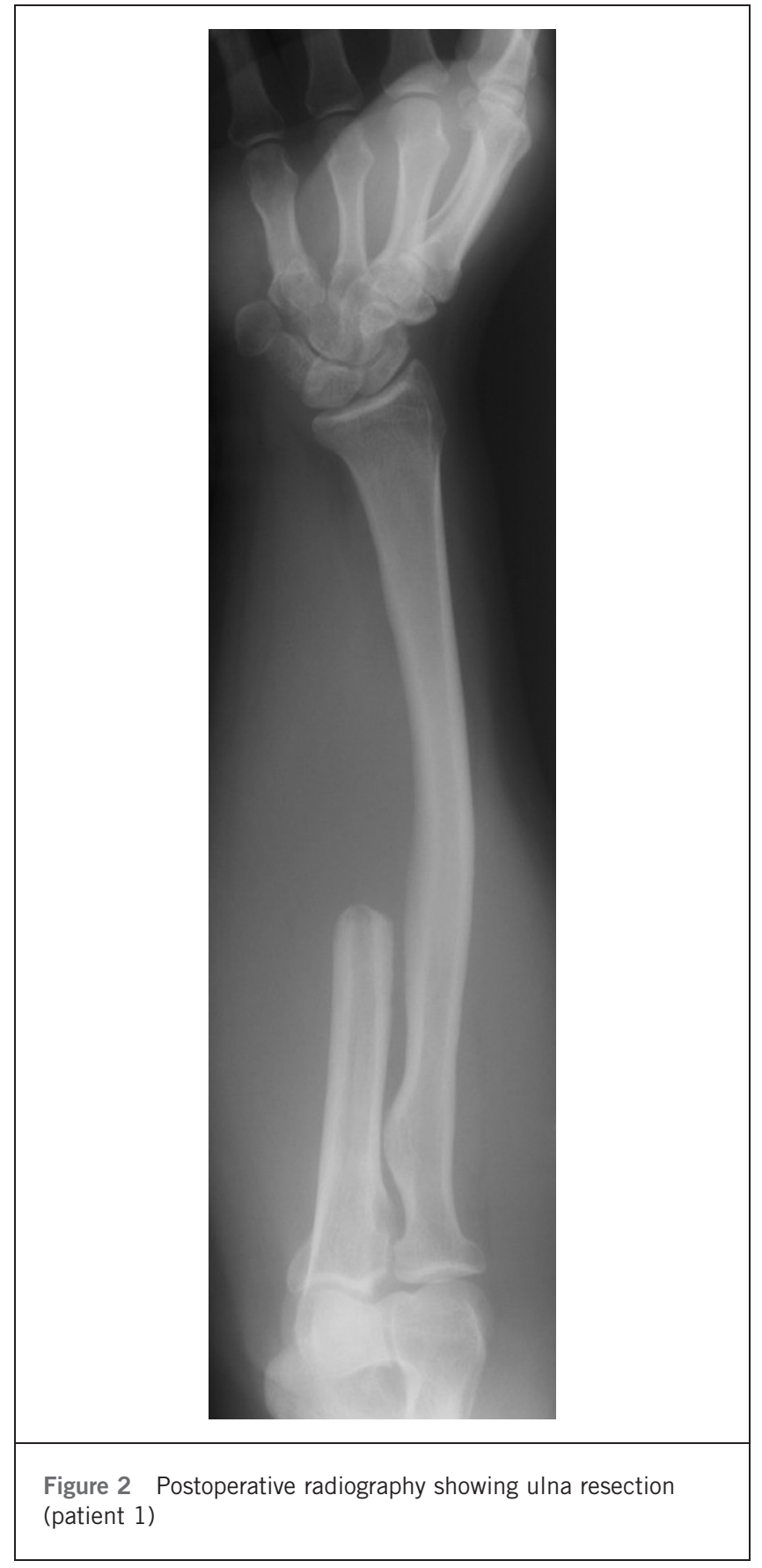




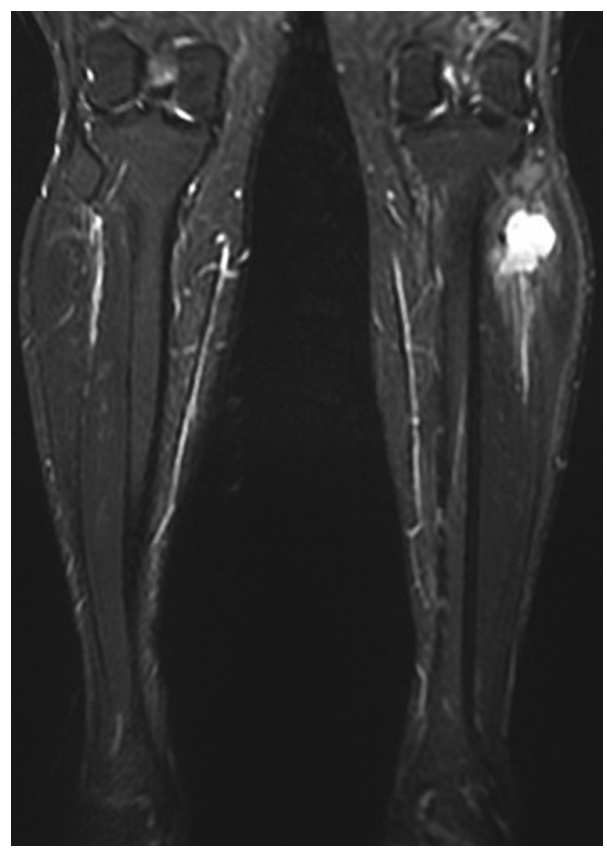

Figure 3 Preoperative coronal magnetic resonance imaging showing lesion in left proximal fibula (patient 2)

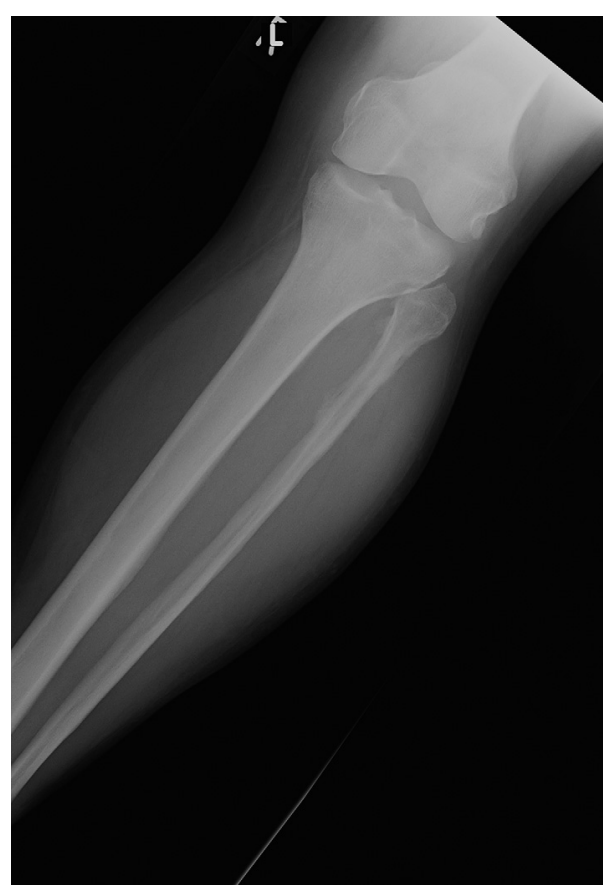

Figure 4 Anteroposterior radiography demonstrating destructive lesion in proximal fibula (patient 2)

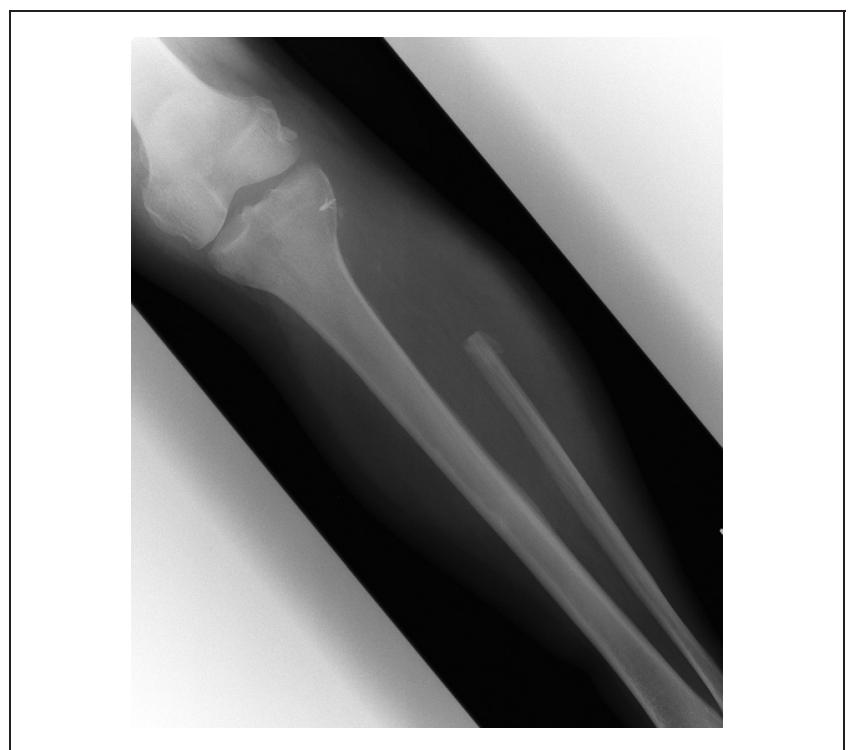

Figure 5 Anteroposterior radiography on last follow-up appointment showing resected proximal fibula and reconstruction of soft tissues with suture anchors (patient 2)

with a suture anchor (Fig 5). Subsequent histological analysis of the full resection specimen confirmed the diagnosis of extra-axial chordoma resected with a wide margin. The patient made an uneventful recovery and remains free of disease at two years without any mechanical symptoms from the knee joint.

\section{Patient 3}

A 68-year-old man presented with a pathological fracture of the distal femur. This was preceded by a five-month history of aching discomfort in the distal thigh. Plain radiography demonstrated an undisplaced fracture through an expansile lesion in the distal femur. Cross-sectional imaging showed non-specific changes. A needle biopsy revealed a low grade malignant tumour, thought to be chondroid in origin. Preoperative workup suggested a solitary lesion, and the patient underwent extra-articular resection and reconstruction with an endoprosthetic replacement of the knee joint (Fig 6). Only after analysis of the whole resection specimen was the diagnosis confirmed as an extra-axial chordoma with a close resection margin.

On follow-up review at 2.5 years after index surgery, the patient was found to have aggressive local recurrence, which was excised. The option of above knee amputation was discussed with the patient. He understood the risk of further local recurrence and systemic metastasis but decided not to have an amputation. He had further local recurrence six months later and was also noted to have systemic metastasis on restaging studies. Following careful discussion in the MDT meeting, the patient was offered palliative therapy and subsequently died four years after initial diagnosis. 


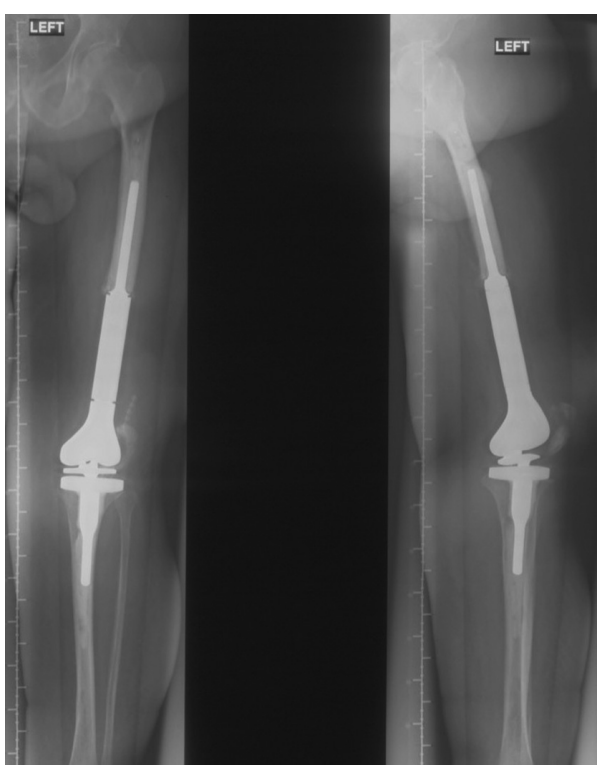

Figure 6 Postoperative radiography of distal femur endoprosthetic replacement. (No preoperative films available at the time of writing.)

\section{Discussion}

The notochord is a rod-shaped mass of vacuolated cells found in axial mesodermal tissue. ${ }^{2}$ It undergoes numerous different stages as the embryo develops and it regresses with advancing maturity. It typically lies immediately below the spinal cord and may provide mechanical strength to the embryo. Chordomas classically occur in several midline locations of the body where the notochord has regressed, such as the sacrococcygeal (approximately 50\% of cases), cranial, spheno-occipital and nasopharyngeal (35\%), and vertebral (15\%) regions. . $^{4,5}$

Clinical presentation can be varied depending on the site involved in the disease process but patients generally complain of localised pain. The diagnosis is frequently delayed as symptoms can be insidious in view of the slow growth of the tumour. ${ }^{7}$

Macroscopically, chordomas tend to form large, multilobulated, bluish-white, myxoid masses that have a friable, mucogelatinous, haemorrhagic consistency. ${ }^{8}$ They are often associated with extension beyond the confines of bone. ${ }^{9,10}$

Microscopically, chordomas are composed of variably sized myxoid lobules separated by fibrous septa. Tumour cells are arranged singly, or in cords or nests. ${ }^{1}$ The cells are variably sized, with abundant clear, eosinophilic or multivacuolated cytoplasm (so-called physaliferous cells). ${ }^{1,8}$ Mild cytological atypia may be present but mitotic activity is low. ${ }^{10}$ Variants to this classical pattern include chordomas with cartilaginous elements (so-called chondroid chordomas) and rare dedifferentiated chordomas. ${ }^{11-13}$
Ultrastructural examination of classic chordomas shows evidence of epithelial differentiation, with the presence of cell junctions and intracytoplasmic lumens with microvillous projections. Membrane-bound glycogen, intermediate filaments and prominent rough endoplasmic reticulum are also found. ${ }^{1}$

The immunohistochemical profile of chordomas includes positivity for cytokeratins (CK1/10, CK8/18, CK19), epithelial membrane antigen, vimentin, and occasionally, S100 protein and carcinoembryonic antigen. ${ }^{14,15}$ Sporadic reactivity is seen for CK 7 and CK20. Actin, desmin, CD31, CD34 and type IV collagen are typically negative. ${ }^{15,16}$

Cytogenetic studies of chordomas show a variety of abnormalities. Hypertriploidy, marker chromosomes, losses of or from chromosomes 1, 3, 4, 10 and 13, and partial or whole copy number gains of chromosomes 7 and 20 have all been described. ${ }^{1,17}$

Chordomas are locally destructive ${ }^{18}$ with a high propensity for local recurrence. ${ }^{4,19}$ Metastatic disease, usually to the lungs, is reported in up to $10 \%$ of cases, with a small number $(5 \%)$ undergoing dedifferentiation to high grade sarcomas. ${ }^{1,8,12}$

Primary treatment should involve radical resection with a wide margin in conjunction with radiotherapy. This has been identified as the most important prognostic factor for overall and disease free survival. ${ }^{19}$ Owing to the location in the axial skeleton, local recurrences cause significant morbidity and mortality, and the mean survival is approximately four years. ${ }^{1}$ Unfortunately, definitive radical surgery is often not possible when the tumour is very close to or involves vital structures. ${ }^{2,4,7,19}$

Radiotherapy is effective but on its own, it will not achieve a cure. ${ }^{1,4}$ A combination of surgery and radiotherapy is the standard treatment. ${ }^{2,4,5,20}$ An extra-axial chordoma is macroscopically and histologically similar to an axial chordoma. $^{2}$ The main difference is location, with extra-axial lesions always located near tenosynovial or bony structures. ${ }^{6}$ Importantly, extra-axial chordomas are generally more accessible so that a wide resection margin is readily achievable, thereby negating the need for adjuvant radiotherapy, such as in the cases described above.

In 1955 Laskowsi documented five cases of extra-axial chordoma. ${ }^{3}$ The term parachordoma was first used by Dabska in 1977 to describe chordoma-like tumours arising outside of the axial skeleton. ${ }^{21}$ Extra-axial chordomas are more difficult to diagnose than conventional chordomas, and it may be difficult to distinguish between an extra-axial chordoma and metastasis of a conventional chordoma. ${ }^{2}$ Despite the location, these tumours are presumed to originate from notochord remnants, albeit ectopic or migratory in nature. ${ }^{1}$

The differential diagnoses include skeletal and extraskeletal chondrosarcoma. ${ }^{22}$ It has been suggested that tissue obtained by needle biopsy is less likely to give a diagnosis for tumours that have complex architecture and cell pleomorphism. ${ }^{23}$ It was for this reason that the cases we described required more tissue (open biopsy/analysis of whole resection specimen) than a needle biopsy can provide to confirm the suspected rare diagnosis. 
The preferred treatment for patients with extra-axial chordoma is radical surgery. Survival, recurrence and rates of metastasis are unknown because of the rarity of this condition. ${ }^{2}$ It is, however, known that the tumour may recur after many years ${ }^{2}$ and that it is thought to seldom metastasise. ${ }^{1}$ Of the 37 cases described in the literature, $6(16 \%)$ recurred between 3 months and 12 years after excision. ${ }^{21,24}$ Long-term, disease free survival can be achieved in most patients with radical surgery alone. ${ }^{2}$ The role of radiotherapy and chemotherapy remains unclear.

\section{Conclusions}

In view of the rarity of this tumour and the difficulty in confirming its diagnosis, we suggest that any suspected case is discussed within a specialist sarcoma MDT so that the correct diagnosis can be achieved and treatment tailored accordingly.

\section{References}

1. DiFrancesco LM, Davanzo Castillo CA, Temple WJ. Extra-axial chordoma. Arch Pathol Lab Med 2006; 130: 1,871-1,874.

2. van Akkooi AC, van Geel AN, Bessems JH, den Bakker MA. Extra-axial chordoma. J Bone Joint Surg Br 2006; 88: 1,232-1,234.

3. Laskowski J. Pathology of Tumors. Warsaw: PZWL; 1955.

4. Antoniades J. Uncommon Malignant Tumors. Philadelphia: Masson Publishing USA; 1982.

5. Tuna H, Aydin V, Bozkurt M, Attar A. Chordoma of the lumbar spine: a case report. Neurocirugia 2005; 16: 169-172.

6. Nielsen GP, Mangham DC, Grimer RJ, Rosenberg AE. Chordoma periphericum: a case report. Am J Surg Pathol 2001; 25: 263-267.

7. Boriani $\mathrm{S}$, Chevalley F, Weinstein JN et al. Chordoma of the spine above the sacrum. Treatment and outcome in 21 cases. Spine 1996; 21: 1,569-1,577.

8. Fletcher CD, Unni KK, Mertens F. Pathology and Genetics of Tumours of Soft Tissue and Bone. Lyon, France: IARC; 2002.
9. D'Haen B, De Jaegere T, Goffin J et al. Chordoma of the lower cervical spine. Clin Neurol Neurosurg 1995; 97: 245-248.

10. Mirra JM. Bone Tumours: Clinical, Radiologic and Pathologic Correlations. Philadelphia: Lea \& Febiger; 1989.

11. Heffelfinger MJ, Dahlin DC, MacCarty CS, Beabout JW. Chordomas and cartilaginous tumors at the skull base. Cancer 1973; 32: 410-420.

12. Meis JM, Raymond AK, Evans HL et al. 'Dedifferentiated' chordoma. A clinicopathologic and immunohistochemical study of three cases. Am J Surg Pathol 1987; 11: 516-525.

13. Morimitsu Y, Aoki T, Yokoyama K, Hashimoto H. Sarcomatoid chordoma: chordoma with a massive malignant spindle-cell component. Skeletal Radiol 2000; 29: 721-725.

14. Fisher C, Miettinen M. Parachordoma: a clinicopathologic and immunohistochemical study of four cases of an unusual soft tissue neoplasm. Ann Diagn Pathol 1997; 1: 3-10.

15. Folpe AL, Agoff SN, Willis J, Weiss SW. Parachordoma is immunohistochemically and cytogenetically distinct from axial chordoma and extraskeletal myxoid chondrosarcoma. Am J Surg Pathol 1999; 23: 1,059-1,067.

16. O'Hara BJ, Paetau A, Miettinen M. Keratin subsets and monoclonal antibody HBME-1 in chordoma: immunohistochemical differential diagnosis between tumors simulating chordoma. Hum Pathol 1998; 29: 119-126.

17. Brandal P, Bjerkehagen B, Danielsen H, Heim S. Chromosome 7 abnormalities are common in chordomas. Cancer Genet Cytogenet 2005; 160: 15-21.

18. Sundaresan N, Galicich JH, Chu FC, Huvos AG. Spinal chordomas. J Neurosurg 1979; 50: 312-319.

19. Fuchs B, Dickey ID, Yaszemski MJ et al. Operative management of sacral chordoma. J Bone Joint Surg Am 2005; 87: 2,211-2,216.

20. Mendenhall WM, Mendenhall CM, Lewis SB et al. Skull base chordoma. Head Neck 2005; 27: 159-165.

21. Dabska M. Parachordoma: a new clinicopathologic entity. Cancer 1977; 40: $1,586-1,592$.

22. Kilpatrick SE, Hitchcock MG, Kraus MD et al. Mixed tumors and myoepitheliomas of soft tissue: a clinicopathologic study of 19 cases with a unifying concept. Am J Surg Pathol 1997; 21: 13-22.

23. Hadjipavlou AG, Kontakis GM, Gaitanis JN et al. Effectiveness and pitfalls of percutaneous transpedicle biopsy of the spine. Clin Orthop Relat Res 2003; 411: 54-60.

24. Abe S, Imamura T, Harasawa A et al. Parachordoma with multiple metastases. J Comput Assist Tomogr 2003; 27: 634-638. 